DOI https://doi.org/10.30525/978-9934-26-019-3-10

\title{
MODEL AND METHOD TO CALCULATE NONLINEAR OSCILLATIONS OF A ROD WITH A LONGITUDINAL NEAR-SURFACE CRACK, WITH ACCOUNT TAKEN OF LOCAL BUCKLING
}

\section{Zaitsev B. P., Protasova T. V.}

\section{INTRODUCTION}

The presence of longitudinal cracks in elements of thin-walled structures is quite likely, in particular for layered composites. When such elements are under alternating bending strain, there appear tensile and compressive stresses directed along the cracks. When the elements are under tensile stress, the cracks do not manifest themselves, and when they are under compressive stresses, there may appear phenomena related to the buckling of the structural equilibrium of material in the volume surrounding the crack. In this case, one of the main tasks of fracture mechanics is to assess the strength of bodies with longitudinally compressed cracks. In the most general setting, this problem was investigated in the papers reviewed in $[1,2]$. According to the developed 3D linearized theory of stability of deformable bodies [3], once the compression stresses have reached their critical level, there occur, in the volume of material surrounding the crack, stress-strain state perturbations, or so-called "local forms of buckling". If the crack is close to the surface, near-surface buckling occurs. The buckling of material in the volume surrounding the crack precedes brittle fracture.

A particularly important task is to assess the strength of layered and fiber composites, which are destroyed through delamination during compression in the direction of reinforcement. In the context of applying the concept of local buckling, a significant number of publications are devoted to this problem, in particular $[4,5]$. In contrast to the specified approach based on strict provisions, approximate beam models were developed [6-10]. Despite the lack of estimates of the accuracy of the assumptions used, "beam" approaches are simpler, more pronounced, and can be successfully used to solve problems of applied mechanics.

The phenomenon of local buckling around a longitudinal crack does not always result in the destruction of material and a further advancement of the 
crack. For example, in the case of a near-surface crack in a rod, the local buckling of its part - the element between the crack and the rod surface, further referred to as the crack-to-surface element (CSE), - occurs once the local compression strain has reached its critical value. With further rod deformation, CSE experiences supercritical deformation, i.e. it is both in a state of compression and bending. In this case, the bending stiffness of the rod changes depending on the magnitude of deformations, which determines the nonlinearity of oscillations.

The task of this paper is to determine the influence of local buckling in a rod with a longitudinal near-surface crack on its characteristics during oscillations. In this case, a "beam" scheme is used to determine both the state of local buckling and supercritical deformation at small displacements. In this work, which has an applied character, the mutual influence of the various phenomena is taken into account - buckling and oscillations. Works of this kind are poorly represented in publications.

\section{A model of a locally buckled rod with a longitudinal crack}

Figure 1 depicts a rod fragment with a longitudinal near-surface crack during bending, with a thin rod-like bucklable CSE of length $2 l$ highlighted with a bold line.

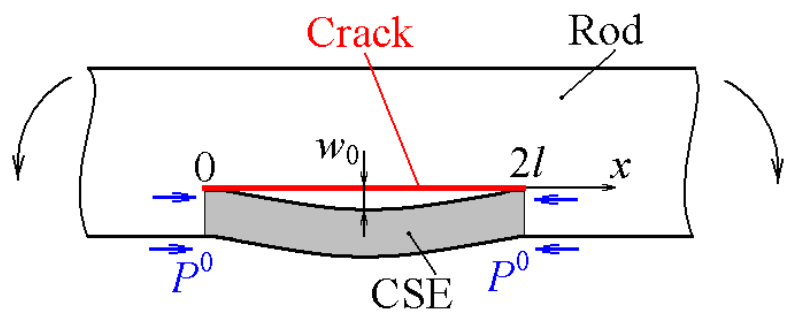

Fig. 1. A model of a rod with a near-surface crack

When the rod undergoes bending, CSE ends experience the relative displacement $u$ along the $x$ axis, the displacement determining the longitudinal force arising in CSE. When the rod undergoes compression after the critical value of $u_{c}$ (critical force) has been reached, CSE buckles and additionally undergoes bending. With a further bending of the rod (increase of $u$ ), there occurs the supercritical CSE deformation, which is considered at small deflections without taking into account the inertia properties during oscillations. Obviously, the rigidity of CSE, as 
part of the rod, changes after buckling, i.e. it is a variable and determined by the dependence $P(u)$, where $P$ is the force in CSE with the relative displacement $u$. The $P(u)$ dependence is to be determined.

For definiteness, we will accept the boundary conditions for CSE displacements $(0,2 l)$ in the form of fixed-ends, although they have a more complex form, intermediate between that of fixed and free support. The displacement $u$ is composed of the power component $u_{p}$ and the geometric component $u_{g}$ [11]

$$
u=u_{p}+u_{g}
$$

The $u_{p}$ and $u_{g}$ components are defined by the formulas

$$
u_{p}=\frac{2 P l}{E F}, \quad u_{g}=\frac{1}{2} \int_{0}^{2 l}\left[w^{\prime}(x)\right]^{2} d x
$$

where $F$ is the cross-sectional area of CSE; $w(x)$ is the deflection of CSE after buckling.

Given the boundary conditions, we take

$$
w=\frac{1}{2} w_{0}\left(1-\cos \frac{\pi}{l} x\right)
$$

where $w_{0}$ is the deflection of CSE in the middle (Figure 1).

In view of (1), (2) we get

$$
u=\frac{2 P l}{E F}+\frac{\pi^{2} w_{0}^{2}}{8 l}
$$

The state of buckling, $P=P_{c}$, where $P_{c}=\frac{\pi^{2} E J}{l^{2}}$ is the Euler force, is reached at $u_{c}=\frac{2 P_{c} l}{E F}=\frac{2 \pi^{2} J}{F l}$. In a subcritical state, at $u \leq u_{c}\left(P<P_{c}\right), w_{0}=0$ and the equilibrium form is rectilinear, at $u \leq u_{c}\left(P<P_{c}\right)$, after buckling, $w_{0} \neq 0$ and supercritical deformation occurs, controlled by the displacement $u$. After buckling at small deflections, the equilibrium state is indifferent, i.e. the supercritical deformation occurs at $P=P_{c}$. The $P(u)$ dependence corresponding to the above is presented in Figure 2. 


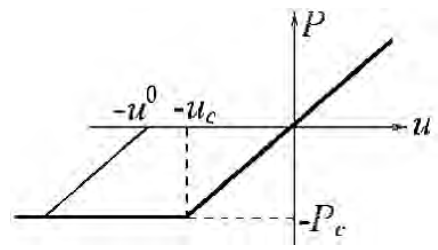

Fig. 2. $P(u)$ dependence for CSE

The variable CSE stiffness also causes the rod stiffness change, depending on the magnitude and sign of the deformation (displacement $u$ ). In CSE deformation calculations, it is appropriate to perform the linearization of the nonlinear dependence $P(u)$ by the initial deformation method [12]. The physical relation for CSE is represented in the form $P=E F\left(\varepsilon-\varepsilon^{0}\right)$, where $\varepsilon^{0}=\frac{u^{0}}{2 l}$ is the additional deformation. The account of the additional deformation in the calculations is equivalent to the application of additional forces at CSE ends, $P^{0}=\frac{u^{0}}{\beta}$, where $\beta=\frac{2 l}{E F}$ is the CSE compliance under static loading; $u^{0}=u-u_{c}$.

In the case of several near-surface cracks, the buckling of CSEs located between the cracks occurs sequentially from the external CSE, adjacent to the surface of the rod, to the internal ones. The calculation formulas and the algorithm of taking into account the CSE stiffness changes are similar to those given above.

\section{A method to calculate the oscillations of a rod with a crack}

To model rod oscillations, the finite element method is used in a three-dimensional formulation with the implementation presented in [13]. The equations of oscillations in matrix form are written as

$$
[\mathbf{M}] \ddot{u}+[\mathbf{C}] \dot{u}+[\mathbf{K}] u=F,
$$

where $[\mathbf{K}],[\mathbf{M}],[\mathbf{C}]$ are the stiffness, mass, and damping matrices; $u, F$ are the displacement and external load vectors.

The modeling of the longitudinal crack in the finite element diagram of the rod is carried out by the method described in [14] according to which constructing a finite element model of a body with a crack consists in breaking the bonds between the nodes of its finite element 
mesh along the surface separating the crack faces. The resulting modified finite element mesh contains a dividing surface that has unconnected double nodes representing the crack faces.

Figures $3 \mathrm{a}$ and $3 \mathrm{~b}$ show the transformation of the finite element mesh for the introduction of a crack. The initial state (Figure 3a) corresponds to a regular grid without a crack, where CS is the crack surface; $C L$ is the crack line; $A, B, C, D$ are finite elements. The transformation of the initial mesh and the formation of an irregular finite element mesh with a crack (Figure 3b) is carried out by selecting the nodes that are initially located on the dividing surface (marked with " $x$ ") and displacing to them the adjacent nodes (marked with "o") (Figure 3a). As a result, double nodes are formed on the dividing surface (Figure $3 \mathrm{~b}$ ), while the finite elements $A$ are transformed into $A$ ', elements $C, D$ degenerate into $C$ ', $D^{\prime}$, and elements $B$ are eliminated.

The application of the described scheme for introducing cuts to account for cracks leads to a change in the main characteristics of the finite element model - the stiffness matrix $[\mathbf{K}]$ and the mass matrix $[\mathbf{M}]$. Their formation for elements $A$ (Figure 3a) is carried out taking into account changes in a number of nodal coordinates, and for elements $B$, taking into account the breaking of bonds between nodes "x" with the adjacent nodes and by the diagonalization of matrices relative to nodes " $\mathrm{x}$ "

$$
\left[\mathbf{K}_{B}\right]=G \cdot \sum_{j} \mathbf{i}_{j} \mathbf{i}_{j}, \quad\left[\mathbf{M}_{B}\right]=g \cdot \sum_{j} \mathbf{i}_{j} \mathbf{i}_{j},
$$

where the dyadic form of the representation of tensors (matrices) is adopted; $\mathbf{i}_{j}$ is the vector in which only the $j$-th component is nonzero and equal to one; $j$ is the index pointing to nodes $\mathrm{x}$ and the components of displacements in these nodes; $G>>1, g<<1$ are, respectively, large and small numbers.

To change the finite elements $C, D$ (Figure $3 \mathrm{a}$ ), in which the number of faces and nodes decreases, formalized procedures of matrix transformations are applied. The modified stiffness matrix [K'] and the mass matrix [ $\left.\mathbf{M}^{\prime}\right]$ of these elements are determined by the dependencies

$$
\left[\mathbf{K}^{\prime}\right]=[\mathbf{A}]^{T} \cdot[\mathbf{K}] \cdot[\mathbf{A}]+G \cdot \sum_{j} \mathbf{i}_{j} \mathbf{i}_{j}, \quad\left[\mathbf{M}^{\prime}\right]=[\mathbf{A}]^{T} \cdot[\mathbf{M}] \cdot[\mathbf{A}]+g \cdot \sum_{j} \mathbf{i}_{j} \mathbf{i}_{j},
$$

where $[\mathbf{A}]=\mathbf{E}-\sum_{j} \mathbf{i}_{j} \mathbf{i}_{j}+\sum_{j, k} \mathbf{i}_{j} \mathbf{i}_{k}$ is the transformation matrix; $\mathbf{E}=\sum_{j} \mathbf{i}_{s} \mathbf{i}_{s}$ is the unit matrix; $k$ refers to nodes "o" and displacements therein. 


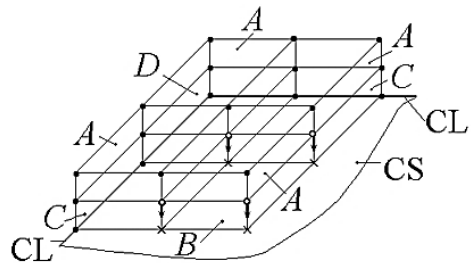

a

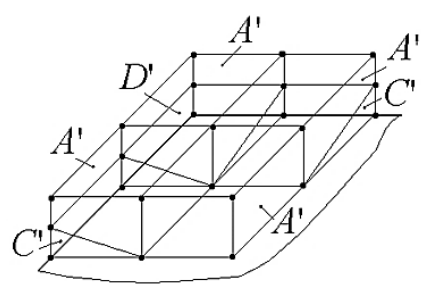

b

Fig. 3. A scheme of mesh transformation with the introduction of a crack

The described scheme allows us to model cracks with complex surfaces, for example, consisting of joined or intersecting planes of different directions, and it does not impose constraints on the number of introduced cracks.

The integration of equations (5) over time is performed by the Wilson finite-difference method [15]. A peculiarity of its application in this case is the introduction of unit forces $P^{0}$ at CSE ends at each integration step, for which the displacement $u$ can be represented as

$$
u=u_{t}+\alpha P^{0},
$$

where $u_{t}$ is the current displacement in the Wilson scheme (excluding additional forces); $\alpha$ is the displacement of CSE ends in the rod from the momentum of the unit forces $P^{0}$ (dynamic compliance). Taking into account the expression for $P^{0}=\frac{u-u_{c}}{\beta}$ by the method of additional deformations and excluding $u$ from equation (6), we obtain the expression for the boundary forces

$$
P^{0}=\frac{u_{t}-u_{c}}{\beta-\alpha} .
$$

The denominator of formula (7) is nonzero, because the dynamic compliance is lower than the static compliance. Additional forces $P^{0}$ at each step are uniquely determined by formula (7) and do not require iterations. A similar approach to taking into account the nonlinearity of individual structural elements was used in [16]. 


\section{A cantilever rod with a single near-surface crack}

A diagram of a rod with a through-the-thickness longitudinal crack is shown in Figure 4.

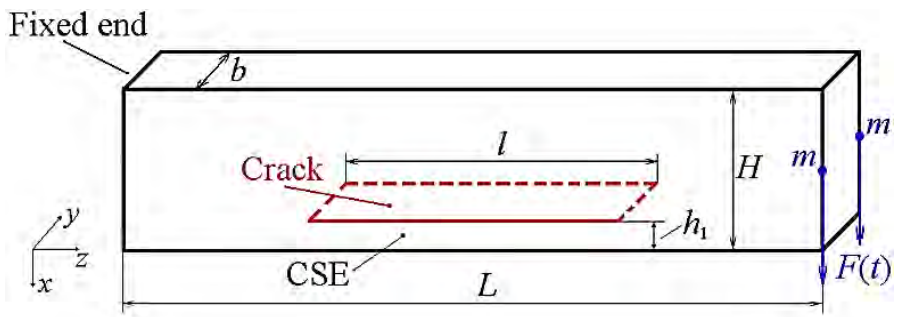

Fig. 4. A diagram of a cantilever rod with a crack

The calculation data are as follows: $L=80 \mathrm{~cm}, b=1 \mathrm{~cm}, H=4 \mathrm{~cm}$, $h_{1}=1 \mathrm{~cm}, l=40 \mathrm{~cm}, E=20.6 \mathrm{MN} \mathrm{cm}{ }^{2}, m=8.15 \mathrm{~kg}$. It is accepted that the rod is massless while performing the function of variable stiffness, and concentrated masses are placed at its end. In this case, the system can be reduced to a single-mass variable stiffness model and analyzed analytically.

Free vibrations of the presented nonlinear system were studied, and the dependence of the frequency of oscillations on their amplitude was determined. Note that due to the asymmetry of the dependence of the restoring force, the maximum deviations of the different signs $A^{+}, A^{-}$ differ. In this case, introduced are the following characteristics: the center of vibrations, $A=\frac{A^{-}-A^{+}}{2}$, and the half-amplitude of vibrations, $A=\frac{A^{-}+A^{+}}{2}$. The dependence of the restoring force, $F\left(w_{m}\right)$, where $F, w_{m}$ is the force at the cantilever end and its displacement (mass $m$ ), is calculated for a static load, and the data are placed in table 1 .

Table 1

Dependence of the restoring force on displacement

\begin{tabular}{|c|c|c|c|c|c|c|c|c|c|}
\hline$F, \mathrm{\kappa N}$ & 2.452 & 0 & $\begin{array}{c}- \\
0.981\end{array}$ & $\begin{array}{c}- \\
1.020\end{array}$ & $\begin{array}{c}- \\
1.472\end{array}$ & $\begin{array}{c}- \\
1.962\end{array}$ & $-\overline{4}$ & $\begin{array}{c}- \\
2.943\end{array}$ & $\begin{array}{c}- \\
3.434\end{array}$ \\
\hline$w_{m}, \mathrm{~cm}$ & 3.801 & 0 & $\begin{array}{c}- \\
1.520\end{array}$ & $\begin{array}{c}- \\
1.582\end{array}$ & $\begin{array}{c}- \\
2.557\end{array}$ & $3 . \overline{6}$ & $\begin{array}{c}- \\
4.679\end{array}$ & $\begin{array}{c}- \\
5.740\end{array}$ & $\begin{array}{c}- \\
6.801\end{array}$ \\
\hline
\end{tabular}


The dependence $F\left(w_{m}\right)$ is bilinear and is represented as

$$
F=\left\{\begin{array}{l}
k_{0} w_{m}, \quad w_{m} \geq w_{c} \\
-F_{c}+k_{1}\left(w_{m}+w_{c}\right), \quad w_{m}<-w_{c}
\end{array},\right.
$$

where $F_{c}, w_{c}$ are, respectively, the values of the force at the cantilever end and its displacements at the moment when CSE buckles $\left(F_{c}=1.020 \mathrm{kN}, w_{c}=1.582 \mathrm{~cm} ; k_{0}, k_{1}\right.$ are the coefficients characterizing the slope of lines in the diagram $\left(k_{0}=1.291 \mathrm{kN} / \mathrm{cm}, k_{1}=0.925 \mathrm{kN} / \mathrm{cm}\right)$.

Free vibrations were caused by the initial deflection of the system during quasi-static loading by the forces $F(t)$ and subsequent drop of load in the presence of a small level of damping. The calculation results for the proposed model and methodology are presented in table 2 .

Table 2

\section{Dependence of the frequency of free oscillations} on amplitude. Proposed model

\begin{tabular}{|c|c|c|c|c|c|c|}
\hline$A, \mathrm{~cm}$ & 1.582 & 1.977 & 2.270 & 3.047 & 3.865 & 4.673 \\
\hline$\Delta, \mathrm{cm}$ & 0.000 & 0.005 & 0.017 & 0.038 & 0.106 & 0.161 \\
\hline$p, \mathrm{~Hz}$ & 10.00 & 9.914 & 9.833 & 9.699 & 9.590 & 9.537 \\
\hline
\end{tabular}

For comparison, we present data for the natural oscillation frequency of a solid rod, $p=10.15 \mathrm{~Hz}$, and a rod with a crack, but without taking into account the CSE buckling, $p=10.0 \mathrm{~Hz}$. The data in table 2 determine the skeletal curve with soft non-linearity, which occurs in this case.

To assess the accuracy of calculating nonlinear oscillations according to the presented method, the frequencies of free oscillations were calculated using the analytical dependence obtained by the direct linearization method [17]. In doing so, the bilinear dependence of the restoring force (8) obtained by calculation was used. The frequency of free oscillations is determined according to the formula

$$
p^{2}=\frac{5}{4 m A^{5}} \int_{-A}^{A} F(u-\Delta) u^{3} d u
$$

where the function $F$ is the restoring force characteristic (8).

The calculation data with the use of formula (9) are presented in table 3 . 
Dependence of the frequency of free oscillations on amplitude. Direct linearization method

\begin{tabular}{|c|c|c|c|c|c|c|}
\hline$A, \mathrm{~cm}$ & 1.582 & 1.977 & 2.271 & 3.031 & 3.866 & 4.673 \\
\hline$\Delta, \mathrm{cm}$ & 0.000 & 0.006 & 0.015 & 0.053 & 0.105 & 0.160 \\
\hline$p, \mathrm{~Hz}$ & 10.010 & 9.952 & 9.886 & 9.741 & 9.633 & 9.562 \\
\hline
\end{tabular}

Comparison of the data in tables 2 and 3, obtained respectively by calculation and analytically, are in good agreement. This indicates the acceptable accuracy of the calculations of nonlinear oscillations with the restoring force characteristic determined by the proposed model. The change in natural oscillation frequencies for the selected range of amplitudes, limited by the magnitude of deflections and stresses to the yield strength, is up to $6 \%$.

\section{A cantilever rod with a system of collinear surface cracks}

The scheme of the rod is similar to the previous example, but additionally, through the thickness of CSE shown in Figure 4, one and two cracks of the same length $l$ were introduced. Accordingly, the following design studies were considered: two cracks (two CSEs with thicknesses $h_{2}=0.5 \mathrm{~cm}$ ) and three cracks (three CSEs with thicknesses $\left.h_{3}=1 / 3 \mathrm{~cm}\right)$. Due to the complexity of the problem, a higher finite element discretization was used. When modeling the oscillations of the rod, a scheme of successive buckling from the external CSE to the internal one was used.

Studies of the nonisochronism of free oscillations were carried out, and amplitude-frequency characteristics were obtained with the identification of various resonances.

The dependencies of the frequency of free oscillations on amplitude for a different number of cracks in the form of skeletal curves (nonisochronism of oscillations) are shown in Figure 5. According to the dependencies, with an increase in amplitude, the frequency of free oscillations for each of the considered options tends to a certain limit. With an increase in the number of cracks, and, correspondingly, a decrease in the $h_{i}$ of CSE, the values involved in the critical displacement $u_{c}$ are matched with $F \sim h_{i}, J \sim h_{i}{ }^{3}$, resulting in $u_{c} \sim h_{i}{ }^{2}$. That is, with an increase in the number of cracks, the CSE resistance to compressive stresses rapidly decreases, which is almost equivalent to the absence of material resistance in the region occupied by the cracks. In the limit, the 
restoring force characteristic, referred to the unit of mass, is bilinear with a kink at the origin of coordinates and the tilt angles $\alpha_{1}, \alpha_{2}$ of the lines in the diagram for positive and negative displacements, respectively. In this limiting case, the system is isochronous, and the frequency of free oscillations is determined by the formula

$$
p_{0}=\frac{p_{1} \cdot p_{2}}{p_{1}+p_{2}}
$$

where $p_{1}^{2}=\operatorname{tg} \alpha_{1}, p_{2}^{2}=\operatorname{tg} \alpha_{2}$.

The stiffness calculations of an inhomogeneous rod with underestimated and initial elastic moduli yielded the values $\operatorname{tg} \alpha_{1}=3.856 \mathrm{sec}^{-2}, \operatorname{tg} \alpha_{2}=2.557 \mathrm{sec}^{-2}$, which determines $p_{1}=9.883 \mathrm{~Hz}$, $p_{2}=8.048 \mathrm{~Hz}$ and, accordingly, $p_{0}=8.872 \mathrm{~Hz}$. The value of $p_{0}$ is close to the limiting frequency value at large oscillation amplitudes for the rod with three cracks.

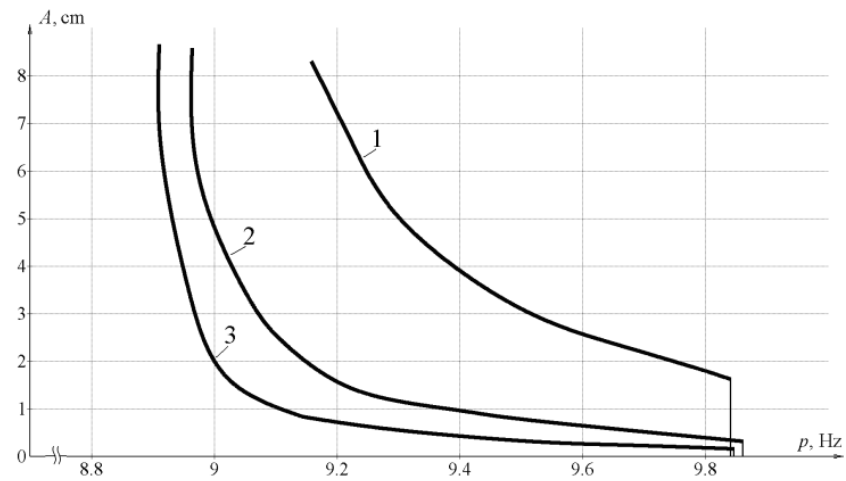

Fig. 5. Skeletal curves for the rod:

1 - with one crack; 2 - with two cracks; 3 - with three cracks

The amplitude-frequency characteristics for the rod with three cracks are constructed for harmonic action by the cantilever force $F=F_{0} \sin \omega t$ with different fixed amplitude values $F_{0}=29.43 \mathrm{~N}$ (3 kgf); $49.05 \mathrm{~N}$ (5 kgf); $98.1 \mathrm{~N}$ (10 kgf) for viscous damping with the logarithmic decrement of oscillations $\delta=0.38$. Such a significant damping is adopted for a higher rate of oscillation stabilization. Figure 6 shows the amplitude-frequency characteristics in the 
region of the main resonance close to the natural frequency of a quasi-linear system. The parameter $\kappa=A / A_{s t}$, where $A$ is the half-amplitude of periodic forced oscillations at the excitation frequency $\omega, A_{s t}$ is the half-amplitude of oscillations at the frequency $\omega=1 \mathrm{~Hz}$ (quasi-static loading). A distinctive feature of the amplitude-frequency characteristics of the rod with a system of three cracks is their dependence on the amplitude of the exciting effect. In particular, the maxima of the amplitude-frequency characteristics are biased, occurring at $9.0 \mathrm{~Hz} ; 9.2 \mathrm{~Hz} ; 9.4 \mathrm{~Hz}$ with a decrease in the amplitude of excitations, and accordingly the amplitude of oscillations. This result is due to the oscillatory properties of the considered nonlinear system, in particular its skeletal curve.

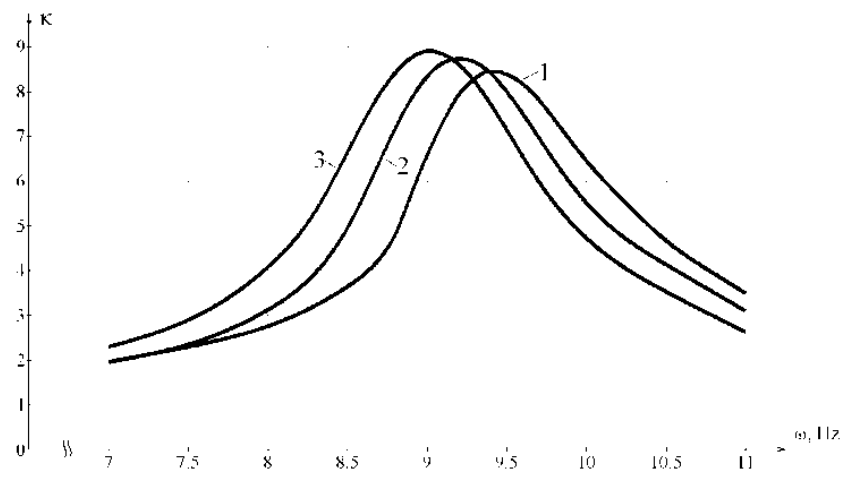

Fig. 6. Resonance curves at different amplitudes of excitation:

$$
1-F_{0}=29.43 \mathrm{~N} ; 2-F_{0}=49.05 \mathrm{~N} ; 3-F_{0}=98.1 \mathrm{~N}
$$

In a wider frequency range, the amplitude-frequency characteristic reveals features due to the presence in the periodic solution of various harmonics that are multiples of the period. Computational studies were carried out for the rod with three cracks at the excitation amplitude $F_{0}=0.981 \mathrm{kN}(100 \mathrm{kgf})$. In the region of lower excitation frequencies (with respect to the frequency of the main resonance), the frequencies $\omega_{2 / 1} \approx 4.5 \mathrm{~Hz}$ and $\omega_{3 / 1} \approx 3.0 \mathrm{~Hz}$ were revealed, for which the second and third harmonics in the Fourier expansion, respectively, have a local extrema. The histograms of frequency analysis are presented in Figure 7, where, also for comparison, a histogram is shown for the case of the main resonance $(\omega \approx 8.9 \mathrm{~Hz})$. The indicated frequencies correspond to the states of super-resonances $2 / 1$ and $3 / 1$, whose oscillatory mode features are illustrated in Figure 8. Thus, with super-resonances, higher harmonics are commensurate with the fundamental 
harmonic, especially with the $2 / 1$ super-resonance, and the damping does not change the harmonic ratio over time.

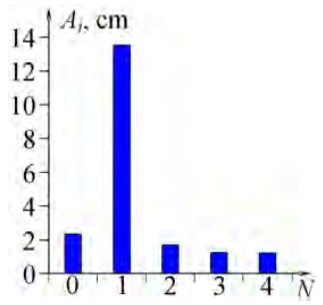

a

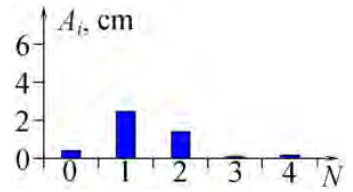

$\mathrm{b}$

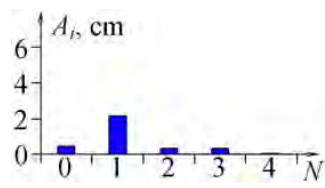

$\mathrm{c}$

Fig. 7. Amplitudes of harmonics at resonant frequencies:

$\mathrm{a}-\omega=8.9 \mathrm{~Hz}$ (main resonance); $\mathrm{b}-\omega=4.5 \mathrm{~Hz}$ (super-resonance $2 / 1$ ); $\mathrm{c}-\omega=3.0 \mathrm{~Hz}$ (super-resonance $3 / 1$ )

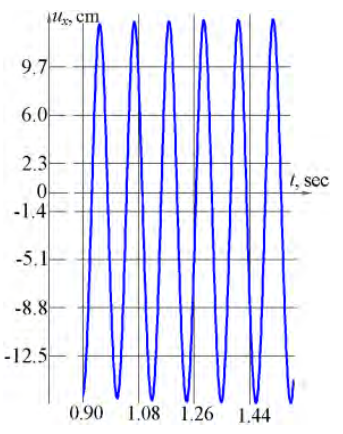

a

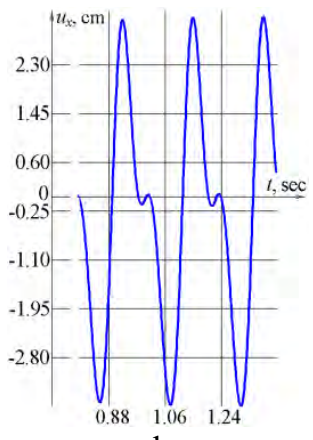

b

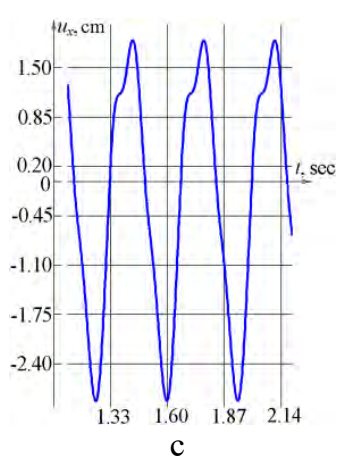

c

Fig. 8. Oscillatory modes at resonances:

$\mathrm{a}-\omega=8.9 \mathrm{~Hz}$ (main resonance); $\mathrm{b}-\omega=4.5 \mathrm{~Hz}$ (super-resonance $2 / 1$ ); $\mathrm{c}-\omega=3.0 \mathrm{~Hz}$ (super-resonance 3/1)

Under high-frequency excitation, in particular at the doubled frequency of the main resonance, $\omega=17.8 \mathrm{~Hz}$ (oscillatory period $\left.T_{\omega}=5.618 \cdot 10^{-2} \mathrm{secs}\right)$, a periodic movement occurs with the frequency $\omega / 2$ (oscillatory period $T_{\omega / 2}=1.124 \cdot 10^{-1} \mathrm{secs}$ ). This can be considered as the appearance of the $1 / 2$ sub-harmonic, which has a local extremum at the indicated frequency, i.e. the $1 / 2$ sub-resonance takes place. The frequency analysis data are placed in table 4, where the amplitude values of the harmonics are indicated for different instants of time (in periods of oscillation $\left.T_{\omega / 2}\right)$. 
Change in the $1 / 2$ sub-harmonic over time

\begin{tabular}{|c|c|c|c|c|c|}
\hline Number of periods $T_{\omega / 2}$ & $A_{0}, \mathrm{~cm}$ & $A_{1 / 2}, \mathrm{~cm}$ & $A_{1}, \mathrm{~cm}$ & $A_{2}, \mathrm{~cm}$ & $A_{1 / 2} / A_{1}$ \\
\hline 8 & 0.117 & 0.528 & 0.647 & 0.002 & 0.816 \\
\hline 16 & 0.104 & 0.283 & 0.653 & 0.002 & 0.433 \\
\hline 24 & 0.101 & 0.170 & 0.654 & 0.002 & 0.260 \\
\hline 32 & 0.100 & 0.106 & 0.655 & 0.001 & 0.162 \\
\hline
\end{tabular}

It is obvious that over time, under the influence of damping, the ratio of harmonics $A_{1 / 2}$ and $A_{1}$ changes significantly, which is evident when oscillatory modes are considered. That is, under the influence of damping over time, the $1 / 2$ sub-harmonic is suppressed.

\section{CONCLUSIONS}

The manifestation of the mutual influence of oscillations and processes of local buckling of layers in rods with near-surface cracks is a new scientific problem. To solve it, a model of a rod with a longitudinal near-surface crack was constructed, which takes into account both the possibility of CSE buckling and supercritical deformation, which causes variable bending stiffness.

A method has been developed for calculating nonlinear oscillations of bodies with cracks, taking into account the buckling phenomenon according to the proposed model, based on the application of the finite element method, linearization of physical relations by the initial deformation method, and solution of the initial problem by the Wilson method.

Studies of the non-isochronism of oscillations of a rod with a single crack and a system of collinear cracks were performed, and skeletal curves were determined. The results are consistent with the data obtained analytically by the direct linearization method with the use the dependence for the restoring force calculated using the proposed method.

The features of the amplitude-frequency characteristics of the rod with three near-surface cracks are studied depending on the excitation amplitude in the region of the main resonance. Super-resonances $2 / 1$ and $3 / 1$, as well as sub-resonance $1 / 2$, were determined and investigated. It is shown numerically that sub-harmonic $1 / 2$ decreases under the influence of damping.

Research development is possible in the following areas:

- clarification of the real conditions for the relationship between CSE and the main structural element; 
- taking into account the geometric nonlinearity of CSE at supercritical deformations, which leads to an increasing dependence of the force in CSE on the displacements of its ends;

- assessment of resultant, due to CSE local buckling, and, as a consequence, due to the change in the type of stress state, stress intensity factors to determine the conditions for the development of cracks during oscillations;

- assessment of the bearing capacity of layered structural elements with separated layers due to local buckling and plastic deformation.

\section{SUMMARY}

A new formulation of the problem is considered, in which the mutual influence of the phenomena of local buckling of a near-surface element near a crack and amplitude-dependent oscillations is taken into account. The buckling of the rod near-surface element, separated by a crack, is determined and controlled by its relative compressive strain. The buckling criterion corresponding to the beam model is applied, and supercritical deformation is considered at small displacements. The rod is deformed by the finite element method in a three-dimensional setting, and a surface crack is modeled using a special technique based on operations with stiffness and mass matrices of an initially solid body. Reduction in stiffness is taken into account according to the additional deformation scheme. Time calculations for nonlinear oscillations are performed by the Wilson finite-difference method with correction at the step of additional forces on the near-surface element. The problems of nonlinear oscillations of a cantilever rod with a single longitudinal crack, as well as with a system of near-surface cracks, are solved. Studies of free small nonlinear oscillations are performed and skeletal curves are determined. Features of the amplitude-frequency characteristics, depending on the amplitude of excitation, in the region of the main resonance of a rod with three near-surface cracks are studied, and super- and sub-resonances are established.

\section{REFERENCES}

1. A. N. Guz, "Establishing the foundations of the mechanics of fracture of materials compressed along cracks (review)", Int. Appl. Mech., vol. 50, iss. 1, pp. 1-57, 2014, doi: 10.1007/s10778-014-0609-y.

2. V. L. Bogdanov, A. N. Guz and V. M. Nazarenko, "Spatial problems of the fracture of materials loaded along cracks (review)", Int. Appl. Mech., vol. 51, iss. 5, pp. 489-560, 2015, doi: 10.1007/s10778015-0710-x. 
3. A. N. Guz, "Osnovy trekhmernoy teorii ustoychivosti deformiruyemykh tel [Fundamentals of the three-dimensional theory of stability of deformable bodies]". Kiyev, USSR: Vishcha shkola, 1986 (in Russian).

4. A. N. Guz, "Osnovy mekhaniki razrusheniya kompozitov pri szhatii [Fundamentals of the mechanics of fracture of composites during compression]: in 2 vols. T. 1. Razrusheniye v strukture materiala [Vol. 1. Fracture in the structure of the material]. T. 2. Rodstvennyye mekhanizmy razrusheniya [Vol. 2. Related fracture mechanisms]". Kiyev, Ukraine: «LITERA», 2008 (in Russian).

5. V. L. Bogdanov, A. N. Guz and V. M. Nazarenko, "Nonclassical problems in the fracture mechanics of composites with interacting cracks". Int. Appl. Mech., vol. 51, iss. 1, pp. 64-84, 2015, doi: 10.1007/s10778-015-0673-y.

6. A. N. Polilov and Yu. N. Rabotnov, "Razvitiye rassloyeniy pri szhatii kompozitov [Development of bundles during compression of composites]". Izvestiya AN SSSR. Mekhanika tverdogo tela-Mechanics of Solids, no. 4, pp. 166-171, 1983 (in Russian).

7. E. I. Grigolyuk, A. A. Kogan and V. I. Mamay, "Zadachi deformirovaniya sloistykh konstruktsiy s rassloyeniyami [Problems of deformation of layered structures with bundles]". Izvestiya RAN. Mekhanika tverdogo tela-Mechanics of Solids, no. 1, pp. 6-32, 1994 (in Russian).

8. V. V. Bolotin, "Stability Problems in Fracture Mechanics". New York, USA: John Wiley and Sons, 1994.

9. L. M. Kachanov, "Delamination buckling of composite materials". Boston, USA: Kluwer Academic Publisher, 1988, doi: 10.1007/978-94009-2819-0.

10.R. Kienzler and G. Herrmann, "Mechanics in material space with applications to defect and fracture mechanics". Berlin, Germany: Springer, 2000, doi: 10.1007/978-3-642-57010-0.

11.A. S. Volmir, "Ustoychivost deformiruyemykh system [Stability of deformable systems]". Moscow, USSR: Nauka, 1967 (in Russian).

12.I. A. Birger and B. F. Shorr, Eds. "Termoprochnost detaley mashin [Thermal strength of machine parts]". Moscow, USSR: Mashinostroyeniye, 1975 (in Russian).

13. N. G. Shulzhenko, P. P. Gontarovskiy and B. F. Zaytsev, "Zadachi termoprochnosti, vibrodiagnostiki i resursa energoagregatov (modeli, metody, rezul'taty issledovaniy) [Problems of thermal strength, vibrodiagnostics and resource of power units (models, methods, results 
of research)]". Saarbrücken, Germany: LAP LAMBERT Academic Publishing GmbH \& Co. KG, 2011 (in Russian).

14. A. V. Asayenok, B. F. Zaytsev and N. G. Shulzhenko, "Metodika vvedeniya razrezov $\mathrm{v}$ skheme metoda konechnykh elementov $\mathrm{v}$ zadachakh statiki i sobstvennykh kolebaniy trekhmernykh konstruktsiy [The technique of introducing cuts in the scheme of the finite element method in problems of statics and natural vibrations of three-dimensional structures]". Problemy mashinostroyeniya - Journal of Mechanical Engineering, vol. 6, no. 3, pp. 58-63, 2003 (in Russian).

15.K-J. Bathe, "Finite Element Procedures". New Jersey, USA: Prentice Hall, 1996.

16. B. Zaytsev, A. Asayenok, T. Protasova, D. Klimenko, D. Akimov and V. Sirenko, "Dynamic processes during the through-plastic-damper shock interaction of rocket fairing separation system components". $J$. of Mech. Eng., vol. 21, no. 3, pp. 19-30, 2018, doi: 10.15407/pmach 2018.03.019.

17.I. I. Blekhman, Ed. "Vibratsii v tekhnike: Spravochnik [Vibration in technology: A Handbook] in six vols. T. 2. Kolebaniya nelineynykh mekhanicheskikh sistem [Vol. 2. Oscillations of nonlinear mechanical systems]". Moscow, USSR: Mashinostroyeniye, 1979 (in Russian).

\section{Information about the authors:} Zaitsev B. P.,

D. Sci. (Engineering), Senior Researcher,

Leading Scientific Researcher of the Vibration and Thermal Strength Research Department, A. Podgorny Institute of Mechanical Engineering Problems of NASU 2/10, Pozharskyi str., Kharkiv, 61046, Ukraine

Protasova T. V.,

Cand. Sci. (Engineering), Senior Researcher of the Vibration and Thermal Strength Research Department, A. Podgorny Institute of Mechanical Engineering Problems of NASU 2/10, Pozharskyi str., Kharkiv, 61046, Ukraine 